\title{
Towards the Establishment of a Reference Framework for Cancer
}

\author{
Abdellatif Maamri \\ Higher Institute of Nurses Professions and Health Techniques of Oujda, Ministry of Health, Oujda, Morocco \\ Email: abdellatifm@hotmail.com
}

Received 22 September 2015; accepted 25 October 2015; published 28 October 2015

Copyright (C) 2015 by author and Scientific Research Publishing Inc.

This work is licensed under the Creative Commons Attribution International License (CC BY). http://creativecommons.org/licenses/by/4.0/

(c) (i) Open Access

\begin{abstract}
This framework is designed to encourage transdisciplinary research that will integrate social determinants in cancer research. This framework is designed to help conceptualize how the social determinants interact with other factors in the etiology of cancer. The factors influencing the populations of cancer in Morocco and other countries of the world can be classified into seven groups: 1) Political and institutional factors, 2) Socio-cultural factors, 3) Socio-economic factors, 4) Environmental factors, 5) Biological factors, 6) Factors related to lifestyle, and 7) Those related to the health system.
\end{abstract}

Keywords

Framework, Cancer, Transdisciplinary, Morocco

\section{Introduction}

Cancer diseases already existed there from 4000 to 5000 years, as evidenced by the work done on the mummies of Pharaonic Egypt. Actually, Cancer is a public health issue globally. It touches all categories of the world's population regardless of their age, their gender or their socio-economic levels. In 2000, 5.3 million men and 4.7 million women worldwide developed cancer and 6.2 million people had died either $12 \%$ of the world population [1]. In industrialized countries, the percentage exceeds 25\% [1]. The frequency of these cancers could increase by $50 \%$ in the next twenty years, with 20 million new cases per year in 2020 and 10 million deaths taking account of current trends in smoking prevalence and adoption patterns unhealthy life [2]. These cancers are no longer diseases of rich societies since already $50 \%$ of cancers occur in developing countries [3].

To overcome this problem, many studies have been made to try to understand the etiology of the disease. While progress has been made in recent decades but there is still much to do, the causes of cancer are numerous, diverse, more intertwined and especially multi-faceted issues of a cumulative effect. INSERM [4] attributed to cancer a double origin, genetic and environmental factors; the concept of environment is interpreted here broad- 
ly. INSERM considers environmental factors: physical, chemical or biological in the atmosphere, water, soil or food whose exposure is experienced and not generated by individual behavior. INSERM [4] also notes that the impact of environmental factors on cancer risk depends on both its link to cervical cancer and the prevalence of exposure to this factor in the population. Thus, an environmental factor conferring even low or moderate increase in the risk of cancer will have a high impact factor if it is widespread in the general population. Conversely, a potent carcinogen same factor will have little impact if very few people are exposed to it. According to WHO, 70\% of cancers are linked to our environment, mostly our lifestyle [5]. Indeed, it is now recognized that environmental exposure is variously involved in the etiology of most cancers [2]. For some, half of cancer cases could be avoided by applying existing etiological knowledge.

After Bray et al. [6], cancer remains the leading cause of death in many high-income countries and will become a major cause of morbidity and mortality in coming decades, in all regions of the world. Assuming trends in HDI countries with very high average apply at the global level, namely the increase in incidence rates of colorectal cancers, breast, prostate, lower stomach cancer incidence rates and cervix, and lung cancer increase in women and drop it in men (in high HDI regions and very high only), the authors estimate that we will have over 22 million of new cancer cases per year by 2030 .

In Morocco, cancer is the 2nd cause of death in Morocco after cardiovascular disease. This is a serious disease that weighs heavily on the health of our citizens and the economy of our country. However, most of these cancers can be prevented; others may be diagnosed and treated at an early stage (40\%).

The aims for this study are to establish a framework that can bring together the various determinants of cancer and risk factors.

\section{Methodology}

More effective interventions to reduce the burden of cancer can be developed and implemented by the adoption of a transdisciplinary framework that takes into account the social determinants of cancer and seeks to discover the interactions between social, environmental, behavioral and biological factors in the etiology of cancer.

To implement this framework, we proceeded to read several Scientifics papers to synthesize the various risk factors cited in the literature. We performed reading different types of documents containing relevant information on the subject of cancer. The sites of the international organizations interested to cancer were also consulted (IARC, WHO, INCa..). Well over 200 relevant articles and more than 30 international locations were consulted in order to exploit and explore the latest scientific data and the most relevant for the implementation of this framework.

Multivariate analysis was also used to search for correlations between parameters in the study (demographic, socioeconomic and reproductive...) on one hand and on the other hand cancer [7] [8]. The principal component analysis (PCA) was used. This is a technique which is useful for the compression and the classification data. The problem is to reduce the dimensionality of a data set (sample) by finding a new set of variables smaller than the original set of variables, which nevertheless contains most of the sample information. It is a descriptive method that aims to represent in graphic form the bulk of the information in a table of magnitude of $\mathrm{j}$ variables and where people are in a j-dimensional space.

\section{Results}

The factors influencing the populations of cancer in Morocco and other countries of the world can be classified into seven groups (Figure 1):

- Political and institutional factors,

- Socio-cultural factors,

- Socio-economic,

- Environmental factors,

- Biological,

- Factors related to lifestyle,

- And those related to the health system.

\section{Discussion}

Cancer is currently one of the major health problems worldwide. Despite recent therapeutic progress these years, 


\section{Individual Specific factors}

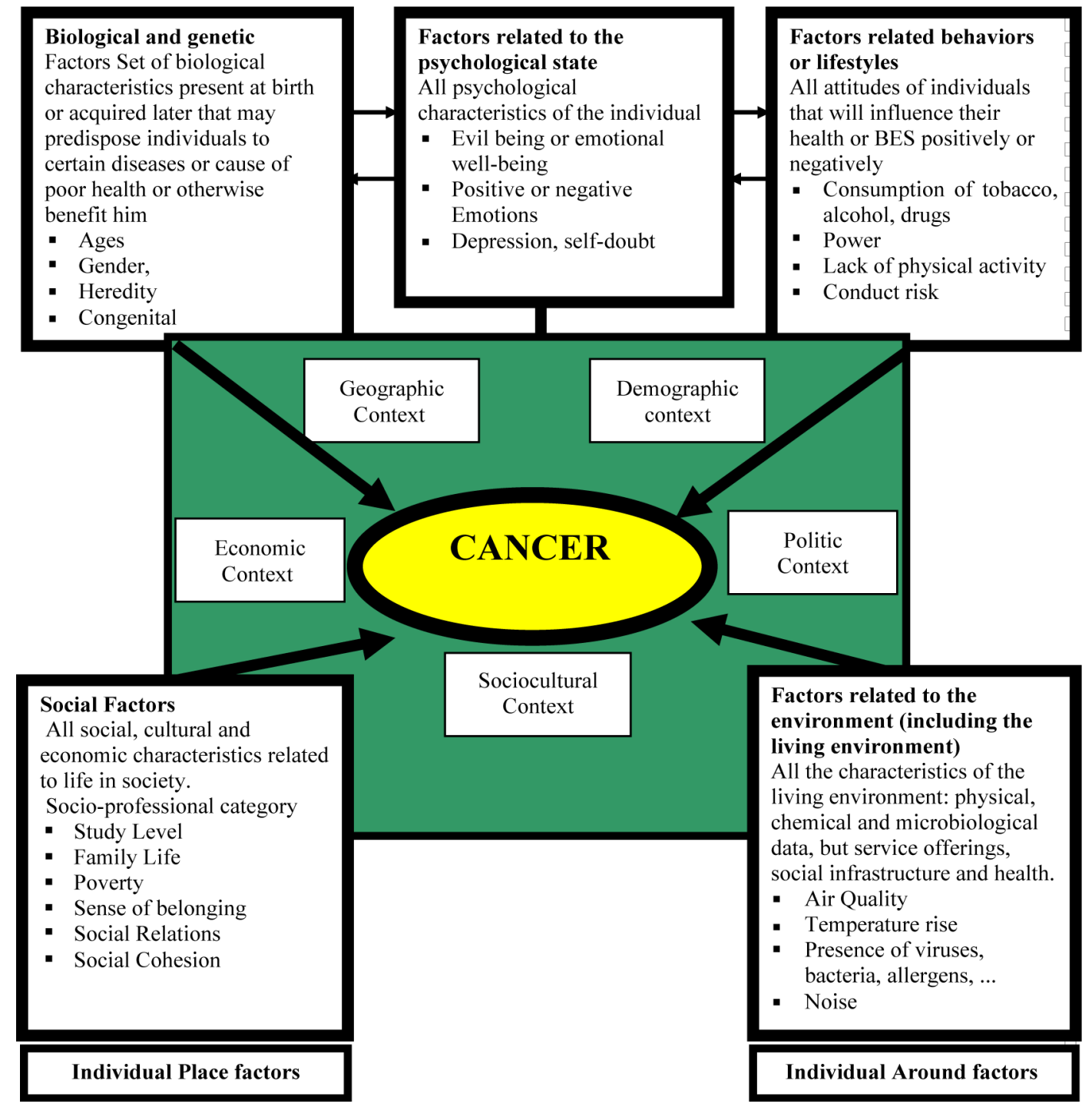

Figure 1. Conceptual framework amount the various determinants of cancer in Morocco.

cancer mortality remains high because the diagnosis is often delayed and the treatment is difficult and often expensive. Much of these cancers can be avoided; others can be detected and treated at an early stage. To effectively fight against this serious disease and that weighs heavily on the health of our citizens and the economy of our country, it is essential to have reliable and accurate data to determine the epidemiological profile of each region in order to establish a strategy adapted to fight.

This framework is designed to encourage transdisciplinary research that will integrate social determinants in cancer research. This framework is designed to help conceptualize how the social determinants interact with other factors in the etiology of cancer...

\subsection{Political and Institutional Factors}

There is a real political commitment from national authorities and their partners in favor of the health sector. But shortcomings in coordination, intersectoral collaboration and funding hamper the implementation of development programs in general and in particular health programs. The fight against cancer is no longer a matter of health ministry's but rather a commitment of the State at all levels and in all departments. 
In Morocco, several actions were developed by health ministry with collaboration with others departments and foundations. On this way, The Lalla Salma Foundation currently supports the Moroccan health system in the fight against cancer. His actions are carried out in close coordination with the Ministry of Health, and various health facilities (hospital, but also basic health care facilities) so that people can have access to better care.

Also, the Ministry of Health has since 2004 developed a plan to fight against cancer in the first place to the establishment of regional oncology centers. Several actions to support cancer have been undertaken by the government to reduce the exorbitant costs for this disease through the reduction of prices of certain drugs and the spread of the Plan to the destitute medical assistance (RAMED).

\subsection{Socio-Cultural Factors}

The low level of education of the Moroccan population health, poverty and prejudice, some beliefs diminish the impact of education activities for a healthy lifestyle hinder the acquisition of favorable attitudes to it. A bad eating habit, associated for some layers to difficulties of access to a balanced diet is the cause of many diseases including cancer.

The level of education is another determinant of cancer in our region. Information on the level of education of individuals was collected by questionnaire resumed five levels: illiterate, preschool, elementary and secondary school, university. Our epidemiological investigation showed that the population after the prefecture of Oujda Angads is mostly illiterate population or preschool with more than 80\% [7] [8]. Skinner et al. [9] in Bulawayo have found that women with breast cancer during 1963-1977 had higher literacy levels than women with other types of cancer. These differences may be due to the prevalence of risk factors among social classes (such as parity, age at menarche and menopause, alcohol consumption). An association between low social status (as measured by literacy) and the risk of cervical cancer was also observed by Skinner et al., [9] in Bulawayo and Chaouki et al. [10] in Morocco who found a strong negative association between social status, family income and level of education [11].

\subsection{Socioeconomic Factors}

The low purchasing power of the population severely limits their access to health care. In general, the increasing impoverishment leads to the use of inexpensive products but often harmful to health, like outdated food or damaged informal trade, or drugs and other non-controlled products.

The dynamism of women in the small business sector is certain, but most of the female population in Morocco remains financially dependent and/or material. For these women, the factor favoring this is limited access to employment because of illiteracy or insufficient level of education.

As the level of education, socioeconomic level was measured indirectly through questions about the profession. Interviewees should indicate whether they are active, retired, unemployed, housewives or students....

Indeed, the health status of the individual and by extension that of the community is strongly conditioned by socio-economic level to the extent that a correct and stable income helps to ensure a sufficient and balanced diet, adequate housing and safe and access to health services and medical care.

The low socioeconomic level is highly found in our study population. Indeed, $81 \%$ of cancer is no occupation which probably results in more risk factors such as stress, psychological disorders as well as physical barriers and economic accessibility that result in the delay in the support some diseases that can worsen and eventually lead to non curable cancers [7]. But it is also a criterion for the delays in the consultation and therefore arrives at a very advanced stage, given the lack of financial and medical coverage generalized basis [12].

Also, the poor population can easily resort to traditional medicine or quackery very answered in the Moroccan population particularly in socioeconomically and culturally slice low, general feature of rural Morocco. Indeed, a study on the perception of Moroccans on cancer pathology showed that the average time between the detection of early signs and the first consultation is one and a half; with a clear difference between socio-professional categories (Lalla Salma Association). In low level of education targets, the occurrence of unusual signs such as nodes, cysts, bleeding, etc. seem to worry that in so far as they continue taking significantly.

The low socio-economic status is a factor favoring especially for infectious cancers such as cervical cancer in women and nasopharynx for both sexes [13] [14]; besides these two types of cancer are present in Morocco oriental and high rates [7].

To illustrate the possible relationship between cancer and low soci-economic level, Arfaoui et al. [13] con- 
ducted a survey of patients with nasopharyngeal cancer at the Marrakech region. This research indicates that the vast majority of patients with this cancer belong to a disadvantaged social class: the socioeconomic status of patients is low in $81 \%$ of cases, average in $18 \%$ of cases and high in $1 \%$ of cases. Similarly, a study by Hubert \& Lamblin [15] confirms that the socioeconomic status of the patient is an additional risk factor for NPC. Skinner et al. [9] in Bulawayo found that women with high socioeconomic level generally have a low parity (1 to 2), breastfeeding rarely do little or not at all, therefore, they had a high risk of cancer.

On the other hand, Friedenreich et al. [16] in their summary report on the review of risk factors for breast cancer related to lifestyle and environment, the authors showed that in Canada socioeconomic status measured in terms of income (income, education ) increased the cancer risk of 1.1 to 3 times to the wealthy as disadvantaged.

In the survey on cancer screening of women, we found that the risk of breast cancer is clearly associated with a high socioeconomic level. This is consistent with literature [12]. These differences may be due to the prevalence of risk factors among social classes (such as parity, age at first menstrual period and menopause...). Similarly and according to the INCA [2], breastfeeding exclusively and ideally until the age of six months remains one of the top recommendations for the primary prevention of cancer. This recommendation goes along with our data because we found a statistically significant difference for breastfeeding for the breast cancer $(p<0.05)$ [8].

\subsection{Environmental Factors}

This estimate is much debated, for lack of criteria by consensus in the scientific community since the role of environmental factors in several cancers is still unclear. The available epidemiological studies are generally insufficient to assess the link between cancer and many exposures to chemicals or physical agents. However, research conducted in recent years has reinforced the idea that environmental factors play a role in cancers.

El Yamani [17] confirmed that more work has to establish links between substances or hazardous situations in our environment and some cancers. However, this relationship is dependent on several variables including the nature of risk factors, the degree and duration of exposure and individual vulnerability to name it.

Besides a genetic origin, INSERM [4] states that it is now recognized that cancers may have an environmental origin. Thus, studies on thousands of Scandinavian twins have identified the part of the environment and heredity in the occurrence of different types of cancer [18]. Other works done on spouses also have contributed enormously to the knowledge of the origins of cancer and particularly important part of the lifestyle [19].

The synthetic mineral fibers, formaldehyde, nanomaterials, the quality of indoor air for benzene are definite or probable carcinogens [20]. Populations exposed to plumes of incinerators between 1970 and 1980 had moderate risk for breast cancer, non-Hodgkin lymphoma, or myeloma.

Moreover INSERM [4] published in 2008 an analysis that shows links with environmental nine cancer sites (lung cancer, mesothelioma, malignant blood diseases, brain tumors, breast cancer, the ovary, testis, prostate and thyroid cancer) whose incidence and mortality have increased since twenties.

It is thus apparent expertise of INSERM and AFSSET that links vary according to officials but also affected locations. To better understand the links between the environment and cancer, we address in the following literature review of this cancer types and their degree of relationship with environmental factors.

Many factors are related to environmental impact population health status. Thus, in terms of housing, housing in rural or suburban areas is precarious and under-equipped. For water, a lot of households use unsafe water. The average quality of that water source is diarrheal and parasitic diseases. Hygiene and sanitation, the mode of excreta disposal is still low quality in some areas.

In terms of evacuation and solid and liquid waste treatment, the problem remains in poor neighborhoods in the absence of efficient system of roads and waste disposal. Just as release to nature of hazardous waste concealing toxic components (batteries, electronic components, waste oil, etc.) are threats to the health of people operating in these areas.

Finally, the intensification of industrial activities and uncontrolled urbanization has greatly changed the living environment of man, exposing it to environmental risks. In our cities, these risks are numerous. Apart from pollution of any kind, simple include waste, hazardous waste, soil degradation, food contamination, exhaust gases and misuse of pesticides and insecticides. Indeed, the agricultural population studies suggest their involvement in brain tumors and hormone-dependent cancers (prostate, breast, testicular, ovarian) [4]. In children, the domestic use of pesticides, in particular household insecticides, by the mother during pregnancy and childhood has been regularly associated with leukemia and, to a lesser extent, brain tumors [4]. 


\subsection{Factors Related to Lifestyle}

Alcoholism, smoking and drug addiction favor the occurrence of diseases like hepatic cirrhosis, hypertension, cancers, and pathologies significant increase in Morocco. Sexual behavior is itself responsible for the high incidence of sexually transmitted infections, particularly hepatitis B and C responsible for cirrhosis and primary liver cancer among others.

Tobacco is cited as the main cause of recognized cancer-related deaths worldwide [21]. WHO said that $80 \%$ of lung cancers are attributable to smoking, which is also the cause of an increased risk for other cancers: oral cavity, pharynx, larynx, pancreas, bladder, kidney, nasal cavity, sinuses, esophagus, stomach, liver, cervix and myeloid leukemia. Similarly, the risk of cancer increases with the dose of ethanol made by alcoholic beverages, no threshold effect [22]. In 2002, it was estimated that in Europe some 150,000 cases of cancer could be directly attributable to alcohol [23]. Therefore, the consumption of alcoholic beverages is the second preventable cause of cancer death, after tobacco [23]. This consumption greatly increases the risk of cancers of the upper aero digestive tract (mouth, pharynx, larynx and esophagus).

In the other hand, several studies Meta-analyzes highlight the relationship between smoking and breast cancer. Johnson (2005) made the following observations:

- Risk associated with passive smoking: 1.27 (CI 1.11 - 1.45) 1.90 (CI 1.53 - 2.37).

- Risk of breast cancer in pre-menopausal associated with passive smoking: 1.68 (CI 1.33-2.12) 2.19 (CI 1.68 2.84).

- Risk associated with active smoking: 1.46 (CI 1.15-1.85) 2.08 (CI 1.44-3.01) and postmenopausal near 2.11 (CI 1.31 - 3.40).

Lee \& Hamling [24], analyzing 14 case-control studies and 8 prospective studies have found that the risk is increased in pre-menopausal women of 1.54 (case-control studies) and 1.02 (prospective studies). Conversely in another case-control study involving 3345 women with breast cancer, witnesses 3454, all post menopausal, Magnusson et al. [25] did not find any statistical association between smoking and breast cancer even in subgroups according to duration of smoking, smoking intensity, age of onset of smoking and the relationship early smoking with the first birth. Similarly, in a case-control study involving 2386 cases and 2502 controls, Lissowska et al. [26] found no risk associated with passive smoking ( $>0.05$ ) but a risk associated with active smoking only in under 45 OR 1.95 (CI 1.38 - 2.76). The risk is not significant among former smokers in this age group but is for current smokers OR 2.03 (CI 1.40 - 2.95). Moreover, in this age group, there is a significant trend of increasing risk by duration of smoking p-trend $=0.04$ (those who smoke less than 10 years 1.57 (CI 1.01 - 2.44) 1020 years and 1.83 (CI 1.15 - 2.91) and more than 20 years OR $2.33(1.32$ - 4.13)) and by smoking intensity (more than 10 pack years OR 2.44 (CI 1.47 - 4.05), but no linear association clear as the top of 14 pack-years, the risk goes down and becomes insignificant $(\mathrm{p}=0.05)$.

\subsection{Factors Related to the Health System}

The health system is inefficient, with unreliable and inefficient funding mechanisms. It only partially meet the demand, hence the increasing use of populations to traditional medicine. The failure of the health system is explained in particular by the unsatisfactory working conditions of health personnel, their uneven distribution between rural and urban areas, the partial implementation of budgets, lack of additional resources, and little Interest paid to health development as part and precondition for socio-economic and human development.

Moreover, social protection is low in Morocco. Traditional mechanisms of social support tend to crumble; a growing part of the population is de facto excluded from the care system. Compulsory Health Insurance whose implementation started in 2007 is still being extended. For now, the widespread RAMED faces a lack of resources at the facility level for a comprehensive and integrated care. For independent and whose workforce exceeds $40 \%$, medical coverage is still in draft form

\subsection{Biological and Genetic Factors}

The genetic component may be responsible for breast cancer in a part of the population. According Sasco [27], the most remarkable discoveries of the last 20 years, in terms of breast cancer etiology, have been made in the field of genetics with the roles of two BRCA1 and BRCA2. Indeed, several studies, agree to consider that women who carry one of these mutations have $45 \%$ - $80 \%$ risk of developing breast cancer as the general popu- 
lation this risk does not exceed $10 \%$. It should be noted that these works were women from the Western countries where the incidence of this cancer is very high. The absence or small number of studies, in Morocco and in developing countries generally does not quantify the role of these mutations in the breast cancer genesis here. In Tunisia, according to a study Monastiri et al. [28] the BRCA1 gene is implicated in 6, 25\% of Tunisian women with a hereditary risk of breast cancer. In the European population, about $2 \%$ of breast cancer may be due to gene mutations, but the proportion of breast cancer is higher among young people such as $10 \%$ below the age of 40 years [29].

\section{Conclusions}

Cancer is a multifaceted and multifactorial disease. This is a very complicated disease involving multiple determinants and risk factors. The framework established by this work takes into account all these determinants with a view to establishing a comprehensive and integrated prevention policy at the country level.

This framework summarizes different risk factors for cancer. Apart from aging and certain hereditary factors, it is possible to influence these factors to prevent illness. Nearly half of cancers could be prevented by stopping smoking, could adopt a healthy lifestyle without alcohol or tobacco and could be supported with a balanced diet with physical activity in a clean environment respectful of human life. These measures may be taken by any person, whether or not with cancer, to reduce the risk of cancer and improve their quality of life.

\section{References}

[1] IARC (2003) Word Cancer Report. In: Stewart, B.W. and Kleihues, P., Eds., IARC Press International Agency for Research on Cancer (IARC) World Health Organization (WHO), Lyon, 342 p.

[2] INCa (2009) La situation du cancer en France en 2009. Collection Rapports \& Synthèses, Ouvrage Collectif Edité par l'INCa, Boulogne-Billancourt, 205 p.

[3] WHO (2014) Fact Sheet No. 297. Updated February 2015. http://www.who.int/mediacentre/factsheets/fs297

[4] INSERM (2008) Cancers et Environnement, Une Expertise Collective. Paris: Edition INSERM, 887 p. Institut de cancérologie Gustave-Roussy. http://www.uicc.org/membership/institut-gustave-roussy

[5] Asselain (2006) Environnement et cancer: Quels sont les risques? Les mardis de l'Institut Curie, Conférence du 12/12/ 2006.

[6] Bray, F., Jemal, A., Grey, N., Ferlay, J. and Forman, D., (2012) Global Cancer Transitions According to the Human Development Index (2008-2030): A Population-Based Study. The Lancet Oncology, 13, 790-801.

[7] Maamri, A. (2012) Etude Epidémiologique \& Bio-statistique de la Pathologie Cancéreuse au Maroc Oriental. Déterminants et facteurs de risque liés à l’Environnement. Université Med I, Faculté des Sciences Oujda, 152 p.

[8] Maamri, A., El hfid, M., Chafi, H. and Boutayeb, A. (2012) Cervix and Breast Cancers in Oujda City in Eastern Morocco: Determinants and Risk Factors. Open Journal of Preventive Medicine, 2, 9-15.

[9] Skinner, M.E.G., Parkin, D.M., Vizcaino, A.P. and Ndhlovu, A. (1993) Cancer in the African Population of Bulawayo, Zimbabwe, 1963-1977: Incidence, Time Trends and Risk Factors (IARC). Technical Report No. 15, Lyon.

[10] Chaouki, N., Bosch, F.X., Munoz, N., Meijer, C.J.L.M., el Gueddari, B., el Ghazi, A., Deacon, J., Castellsague, X. and Walboomers, J.M.M. (1998) The Viral Origin of Cervical Cancer in Rabat, Morocco.

[11] Kogevinas, M., Pearce, N., Susser, M. and Boffetta, P. (Eds.) (1997) Social Inequalities and Cancer. IARC Scientific Publications, Lyon IARC, No. 138.

[12] Ben Abdallah, M., Achour, N., Saadi, A., Boussen, H., Ben Romdhane, K., Hechiche, M., Hsairi, M., Maalej, M., Zehani, S. and Ben Ayed, F. (2009) Cancer du sein en Tunisie: Caractéristiques épidémiologiques et tendance évolutive de l'incidence. La Tunisie Médicale, 87, 417-425.

[13] Arfaoui, A., Soulaymani, A., Quyou, A., Habib, F. and Choulli, K. (2006) Le cancer du cavum au Maroc. Etude épidémiologique sur l'échantillon: Centre d'oncologie Al Azhar de Rabat. Antropo, 14, 75-82.

[14] Ammor, S., Baali, A., Hubert, A. and Cherkaoui, M. (2001) Facteurs alimentaires et environnementaux de risque du cancer du rhino-pharynx dans la région de Marrakech. Bulletins et Mémoires de la Société d'Anthropologie de Paris, 13, 237-249. http://bmsap.revues.org/6191

[15] Hubert, A. and Robert-Lamblin, J. (1988) Apport de l'anthropologie aux enquêtes épidémiologiques: Le cas du cancer du rhinopharynx. Bulletins et Mémoires de la Société d'Anthropologie de Paris, 5, 35-45. http://dx.doi.org/10.3406/bmsap.1988.1656

[16] Friedenreich, M.C., Bryant, H.E. and Courneya, K.S. (2001) Case Control Study of Life Time Physical Activity and 
Breast Cancer Risk. American Journal of Epidemiology, 154, 336-354. http://dx.doi.org/10.1093/aje/154.4.336

[17] El Yamani, M., Vergriette, B., Merle, A., Potelon, J.L. and Hazebrouk, B., AFSSET (2005) Santé et environnement. Enjeux et clés de lecture. Maison Alfort, Afsset, 100 p.

[18] Lichtenstein, P., Holm, N.V., Verkasalo, P.K., Iliadou, A., Kaprio, J., Koskenvuo, M., Pukkala, E., Skytthe, A. and Hemminki, K. (2000) Environmental and Heritable Factors in the Causation of Cancer-Analyses of Cohorts of Twins from Sweden, Denmark, and Finland. New England Journal of Medicine, 343, 78-85. http://dx.doi.org/10.1056/NEJM200007133430201

[19] Hemminki, K., Dong, C. and Vaittinen, P. (2001) Cancer Risks to Spouses and Offspring in the Family-Cancer Database. Genetic Epidemiology, 20, 247-257. http://dx.doi.org/10.1002/1098-2272(200102)20:2<247::AID-GEPI7>3.0.CO;2-U

[20] AFSSET (2008) Cancer et environnement. Paris, ISERM, 889 p.

[21] WHO (2008) Estimates of Worldwide Burden of Cancer in 2008: GLOBOCAN 2008.

[22] INSERM (2005) Cancer: Approche méthodologique du lien avec l'environnement. Paris, INSERM, AFSSE, 92 p.

[23] INCa/NACRe (2007) Alcool et risqué de cancers. Etat des lieux des donnees scientifiques et recommandations de sante publique. Rapports \& syntheses. www.e-cancer.fr

[24] Lee, P.N. and Hamling, J.S. (2009) Systematic Review of the Relation between Smokeless Tobacco and Cancer in Europe and North America. BMC Medicine, 7, 36. http://dx.doi.org/10.1186/1741-7015-7-36

[25] Magnusson, C., Wedrén, S. and Rosenberg, L.U. (2007) Cigarette Smoking and Breast Cancer Risk: A Population Based Study in Sweden. British Journal of Cancer, 97, 1287-1290. http://dx.doi.org/10.1038/sj.bjc.6604007

[26] Lissowska, J., Brinton, L.A., Zatonski, W., Blair, A., Bardin-Mikolajczak, A., Peplonska, B., Sherman, M.E., Szeszenia-Dąbrowska, N., Chanock, S. and García-Closas, M. (2006) Tobacco Smoking, NAT2 Acetylation Genotype and Breast Cancer Risk. International Journal of Cancer, 199, 1961-1969. http://dx.doi.org/10.1002/ijc.22044

[27] Sasco, A.J. (2003) Breast Cancer and the Environment. Hormone Research in Paediatrics, 60, 50. http://dx.doi.org/10.1159/000074500

[28] Monastiri, K., Ben Ahmed, S., Presneau, N., Bignon, J.Y. and Chouchane, L. (2002) Dépistage rapide des mutations germinales du gène BRCA1 par le test de la protéine tronquée chez les familles tunisiennes. La Tunisie Médicale, $\mathbf{8 0}$, 515-518.

[29] Collaborative Group on Hormonal Factors in Breast Cancer (2001) Collaborative Group on Hormonal Factors in Breast Cancer. Familial Breast Cancer: Collaborative Reanalysis of Individual Data from 52 Epidemiological Studies including 58,209 Women with Breast Cancer and 101,986 Women without the Disease. The Lancet, 358, 1389-1399. http://dx.doi.org/10.1016/S0140-6736(01)06524-2 